\title{
Institutional theory and the cross-national transfer of employment policy: the case of 'workforce diversity' in US multinationals
}

\author{
Anthony Ferner*, Phil Almond + and Trevor Collingt:
}

\section{Published in the Journal of International Business Studies, 36, 3,} 304-21, 2005.

This is a post-peer-review, pre-copyedit version of an article published in Journal of International Business Studies. The definitive publisher-authenticated version: Ferner, A.M., Almond, P. and Colling, T. (2005) Institutional theory and the cross-national transfer of employment policy: The case of 'workforce diversity' in US multinationals. Journal of International Business Studies, 36 (3), pp. 304-321. is available online at: $\underline{\text { http://dx.doi.org/10.1057/palgrave.jibs.8400134 }}$

* Leicester Business School, De Montfort University, UK.

† Leicester Business School.

HWarwick Business School (formerly Leicester Business School).

Corresponding author:

Anthony Ferner Department of HRM Leicester Business School

De Montfort University

The Gateway

Leicester LE1 9BH. 
afhum@dmu.ac.uk

tel. +44(0)116 2506441 ; fax +44(0)116 2517548

running title: Institutional theory and cross-national transfer of employment policy

keywords: US multinationals; international HRM; employee diversity; policy transfer; institutionalism

\section{Abstract}

This paper uses a comparative institutionalist approach combined with a power/interests perspective to examine the processes whereby diversity policy is 'internationalized' by US multinational companies. It argues that the process of policy transfer to UK subsidiaries is complicated by incomplete and contested 'institutionalization' of diversity within the US itself, and by differing conceptions of diversity between the US and the UK. The ability of actors within the UK subsidiaries to mobilize and deploy specific power resources allows them to resist the full implementation of corporate diversity policy, leading to a range of compromise accommodations. It is argued that the findings have more general implications for analyzing the transfer of HR practices between national business systems. 


\section{Institutional theory and cross-national transfer: the case of 'workforce diversity' policy in US multinationals}

\section{Introduction}

One of the key issues in the theory and practice of international business is the transfer by multinational companies (MNCs) of policies and practices between the different national business systems in which they operate. International transfer is a process whose specific complexity lies in the need to transmit between two institutional 'domains' that differ in important respects. Such differences go beyond those found within the same national business 'space', and raise questions about how practices originating in one national institutional sphere are incorporated into a significantly different one.

The paper explores this issue through an empirical study of one area of global corporate activity: international workforce 'diversity' policies within American MNCs. The idea of diversity is understood in a wide variety of ways, but in the American context the predominant emphasis has been on the diverse gender and ethnic composition of the workforce. Diversity appears to have been poorly studied so far in an international context. It is of particular interest here because it has very clear roots in a domestic American policy agenda, and its applicability in different business contexts outside the USA is at first sight problematic. It therefore has the potential to throw particular light on the relationship between features of a parent business system and the internationalization of policy. The paper considers the transfer of policies to UK subsidiaries of US companies. The theoretical contribution of the paper lies in its examination the key business issue of cross-national transfer policy in the light of comparative institutional theory.

The first section examines the literature on cross-national transfer in the context of debates on the nature of institutions, and particularly Christine Oliver's (1991) contribution on organizations' strategic responses to institutional pressures. The following section considers the substantive area of diversity as it has emerged in US corporations, arguing that it reflects a specifically American policy agenda. Moreover, the diversity agenda is subject to considerable strains that render it a 'contested institutional terrain'. It is suggested that this institutional context strongly colours the characteristics of international diversity policy within MNCs. Following a section describing research methods, the fourth section presents 
data on international diversity policy from in-depth case studies in US MNCs. The discussion draws out the implications of the findings, in particular for models of international policy transfer within MNCs.

\section{Multinationals and the cross-national transfer of policy}

In the business literature a variety of factors have been put forward to explain patterns of cross-national transfer within MNCs. These may be categorized as factors to do with the structure and strategy of multinationals; the properties of particular practices and policies; and the nature of the national systems between which policies are being transferred. More attention will be devoted to the third of these as it is critical for an understanding of crossnational transfer, and since it interacts with both structural factors and with the transferability characteristics of practices.

In terms of structural factors, policy transfer is likely to be affected by the role that a subsidiary plays within the overall MNC (e.g. Ghoshal and Nohria, 1993); the extent of interdependencies between units (e.g. Taylor et al., 1996); and the nature of intra-corporate and external networks in which subsidiaries are embedded (e.g. Zanfei, 2002). For example, a subsidiary that is highly integrated into the wider MNC and whose function is to execute strategies devised at HQ is more likely to be the recipient of transferred knowledge and practice (Gupta and Govindarajan, 1991). This approach has been applied to the transfer of HR policy specifically (e.g. Edwards and Ferner, 2004; Florkowski, 1996; Schuler et al., 1993; Taylor et al., 1996).

Second, at the level of specific practices, researchers (e.g. Szulanski 1996; Lam 1997) have analysed the factors encouraging or reducing transferability. In general, the crossnational 'stickiness' of a practice depends on such factors as the degree to which the relevant knowledge is tacit or 'codified'; and the extent to which there is 'causal ambiguity', where the precise reasons for success or failure in reproducing a practice in a new context are unclear (Szulanski 1996: 31). More generally, scholars adopting the 'resource-based' view of the firm, have argued that transfer of a policy is more likely to occur where policies are a source of international competitive advantage for the MNC (e.g. Taylor et al., 1996). 


\section{International transfer and national institutions}

The third set of factors in international transfer concerns the nature of differences in business organization and institutions between the MNC's country of origin and the subsidiary's country of operation. There have been various approaches to conceptualizing the nature of such cross-national differences. For two decades the business literature was dominated by 'culturalist' perspectives, stemming from Hofstede (1980) and his followers. These approaches, focusing on national variations in cultural values, have often been highly reductionist, assessing differences between countries in terms of simplistic cultural indices that fail to take into account crucial differences in business institutions and organization in different national business systems. The culturalist approach is also essentially ahistorical, seeing values as constant characteristics of national mindsets, and hence is unable to deal with changes in business systems over time.

More recently, increasing attention has been paid to understanding complex differences between national business systems in the institutions governing how product, labour and financial markets work and how market actors relate to each other (e.g. Lane, 1989; Hall and Soskice, 2000; Whitley, 1999). Such cross-national differences place various degrees of constraint on the international dissemination of practices within MNCs (Ferner, 1997; Whitley 2001).

This 'comparative-institutionalist' approach, rooted in traditions of comparative historical research (e.g. Mahoney and Rueschemeyer, 2003), draws on, but in many respects goes beyond, the American strand of 'new institutionalism' (e.g. DiMaggio and Powell, 1983; Scott, 1995; Zucker, 1988). The new institutionalism emphasizes the importance of normative and cognitive frameworks in understanding organizations' behaviour. It has only recently turned its attention to conceptualizing the interaction of different national institutional frameworks (see e.g. Kostova and Zaheer, 1999; Kostova and Roth, 2002; Tempel and Walgenbach, 2003).

Kostova (1999) has proposed the concept of 'institutional distance' as a key variable in the transferability of practices between national institutional domains. Institutional distance is the difference between the 'country institutional profile' (CIP) of the country of origin and country of operation respectively. The CIP construct provides indices of the regulatory, normative and cognitive institutions of a country (borrowing from Scott's institutional 'three pillars', 1995). Kostova cites the example of a CIP for equal employment opportunity in the 
United States. This would comprise the regulatory institutions such as the relevant legislation; cognitive institutions, i.e. people's shared social knowledge on equal opportunity; and normative institutions, i.e. people's beliefs, values, and norms concerning equal opportunity.

For Kostova, if a practice is not consistent with the recipient country's cognitive institutions (i.e. those establishing taken-for-granted routines of thought and action, and models for interpreting reality - Scott, 1995), subsidiary employees are likely to have difficulty in interpreting and judging the practice correctly, and hence transfer will be impeded. National-institutional factors thus interact with the individual properties of practices; for instance, as Lam (1997) shows, work organization systems tend to be less codified and more tacit in the Japanese business system, impeding their smooth transfer to the UK. Conversely, US MNCs, because of the existence in the American business context of systems for codifying and disseminating knowledge, have a greater organizational capacity for coordinating globally dispersed learning (Lam, 2003).

In addition to 'institutional distance', transfer between different business systems is likely to be shaped by macro-level power relations between countries. Smith and Meiksins (1995) have coined the term 'dominance effects' to describe the hierarchical relationships between national economies within the global economy. Firms from countries lower in the hierarchy may perceive an interest in adopting practices from those based in more dominant economies. Conversely, firms in dominant economies may tend to assume that their practices are superior and capable of transfer to less dominant hosts.

Transfer is not an either-or matter. A transferred practice can be implemented in the subsidiary in a variety of ways. A growing literature exists on the transmutation or 'hybridization' of internationally transferred policies (e.g. Boyer et al., 1998; CutcherGershenfeld et al., 1998: ch. 3; Doeringer et al. 2003; 2000). Indeed, Tolliday et al. (1998: 12) argue that 'systems cannot be transferred without being significantly reshaped.... Hybridization... is inevitable.' Hybridization arises from 'interaction with different national, legal, or institutional systems; different political contexts; different labour markets and skill structures; different infrastructures' (p.4), as firms attempt to make practices drawn from one 'social and economic space' compatible with the constraints and opportunities of the host environment. Though writers such as Boyer et al. see hybridization as playing a critical role in organizational learning, other writers are concerned with the loss of functionality of practices transferred from their original location. Kostova (1999) draws a distinction between 
'implementation' and 'internalization' in the host subsidiary. Implementation involves formal adherence to the practice; internalization refers to the way in which employees attach meaning to the practice or 'infuse it with value'. In other words, she is concerned with cognitive and normative integration of the practice within the subsidiary.

\section{Power, interests and the cross-national transfer of practices}

Much of the literature on transfer implicitly adopts a rationalistic, unitary view of the corporation. Transfer takes place where top management see it as a source of international competitive advantage (e.g. Florkowski, 1996; Taylor et al., 1996). In such analyses, the interests and rationale guiding the behaviour of other actors within the MNC are not generally considered. As a result, there is inadequate exploration of the importance of power relations in mediating the transfer of policies.

In the mainstream business literature, power is not altogether neglected. An important strand (e.g. in the work of Taylor et al., 1996; Martínez and Ricks, 1991) is the concept of resource dependency, drawing particularly on Pfeffer and Salancik (1978). Taylor et al. (1996: 975), for example, note that headquarters 'will attempt to exert high levels of control over their global innovators, but these affiliates will simultaneously have the power to resist these central efforts' (p. 975). However, there is little elaboration of the dynamics of parentsubsidiary power relations.

An important exception to this failure to explore power dynamics is the work of Birkinshaw (see Birkinshaw, 2000; Birkinshaw and Fry, 1998; Birkinshaw and Hood, 1998), which has focused attention in recent years on the way in which subsidiaries build up resources and 'capabilities' (the capacity to deploy resources) over time. Birkinshaw is primarily concerned with the way in which subsidiaries pursue global 'charters'. However, his analysis is pertinent to the issue of policy transfer, since it throws light on the resources available to subsidiaries to negotiate the 'terms of transfer'. Thus subsidiaries engage in a political process, based on 'proactive, pushy, and sometimes Machiavellian tactics' (Birkinshaw and Fry, 1998: 52), whereby they acquire credibility, reputation, and 'track record'; network with key personnel at the corporate centre; and construct international alliances and coalitions with other groups within the MNC.

If subsidiaries have power resources and the ability to resist transfer, then it is likely, as Birkinshaw has shown for the case of charter-building, that transfer will be a negotiated 
process, rather than an 'either-or' one, and that, for example, a practice may be transferred to a subsidiary in a form modified by negotiation with subsidiary actors. Negotiation may take place with senior subsidiary management, or at lower levels within the subsidiary where, as Cutcher-Gershenfeld et al. (1998: 46) observe, 'negotiation' includes 'informal interactions in which practices are considered, debated, tested, and incorporated into people's daily routines'.

The importance of power and interests in the transfer process raises questions about the new institutionalist approach. Unlike some of the more rationalistic resource-based models of policy transfer, this approach is sensitive to processes in the subsidiary. For example, new institutionalists have begun to explore competing 'isomorphic' pulls ${ }^{1}$ from institutional frameworks within the MNC and within the local institutional domain (e.g. Rosenzweig and Singh, 1991; Rosenzweig and Nohria, 1994; Kostova and Zaheer, 1999). Kostova (1999), as discussed, considers the taken-for-granted cognitive and normative frameworks of subsidiary employees in the 'internalization' of transferred policy. But, in common with new institutionalists generally (see DiMaggio, 1988), she pays scant attention to the role of power and interests in this process.

Nonetheless, as Oliver (1991) has persuasively argued, it is in principle possible to synthesize the insights of the new institutionalism with those of a power-based perspective. Oliver explores the scope for organizations to negotiate over the terms of their conformity to institutional pressures. Organizations are able to deploy a range of strategic responses, running from full adherence, through avoidance (e.g. hiding non-conformity under a façade of ritual compliance) and compromise, to full-blooded resistance. Compromise emerges, for example, where there are conflicting institutional demands and expectations; defiance is likely to occur when the organization's 'internal interests diverge dramatically from external values' (p.157). In general, the variables that influence such strategic responses include the dependency of the organization on the source of institutional norms; the perceived legitimacy of the norm; the efficiency gains from conformity; and the multiplicity and consistency of institutional constituents - as Oliver argues (p.162), the 'collective normative order of the environment... is not necessarily unitary or coherent'.

Oliver's analytical framework has clear relevance for the transfer of practices within MNCs between national institutional domains. In particular, management in the host subsidiary is subject to rival institutional pressures emanating from at least two normative, 
cognitive and regulatory frameworks, that of the local environment and that of the parent company and (indirectly) its country of origin. This creates conditions in which subsidiary resources can be deployed to shape the impact of institutional pressures. Moreover, the MNC headquarters-subsidiary relationship gives rise to a situation in which distinct cognitive frameworks exist side by side. This juxtaposition may allow normally concealed and 'takenfor-granted' cognitive schemas and their underlying assumptions to be rendered 'visible', and hence subject to manipulation or challenge. In the new institutionalist approach, cognitive frameworks are divorced from a power perspective. But they may be seen as a terrain for the mobilization of power and interests as different organizational groups seek to win control over the meanings, assumptions, and definitions of organizational practices and processes.

The question of transfer between national institutional frameworks links directly with issues of power and interests. Not only do institutional structures in the host country directly constrain the scope for international transfer of policies within MNCs; in addition, actors in the subsidiary derive power resources from their embeddedness in the local institutional context. For example, subsidiary managers' role as 'interpreters' of the limitations and possibilities of corporate action in the local environment gives them power to negotiate over the terms of transfer of policies, since the significance for corporate action of local business institutions is to a degree indeterminate. Moreover, local managers are involved in close relationships with other local actors within institutionally-influenced (or even prescribed) structures, such as collective bargaining machineries or forms of collective employee involvement such as works councils. This may increase the incentive for local managers to resist transfers of practices in case they disrupt existing relationships. As noted, Boyer et al. (1998) argue that transfer leads to a process of 'creative' hybridization whereby an original practice undergoes dynamic modification and improvement. Equally, however, from a power perspective, subsidiaries may use their power resources to deflect a practice from its original function or content, leading to what might be called 'resistive' hybridization, or to engage in ritual compliance that drains the practice of meaning (cf. Oliver, 1991).

Drawing on this review, we may formulate the following key issues concerning the international transfer of workforce diversity practices within MNCs. First, to what extent do diversity agendas reflect institutional elements specific to the country of origin? How far, moreover, do factors such as system dominance effects shape perceptions of the transferability and competitive advantage of diversity policies? Second, to what extent and in what manner is the original policy hybridized in the recipient unit? Third, to what extent do 
power resources deriving from cross-national differences in institutional environments affect the transfer process?

\section{Workforce 'diversity' and the US business system}

The argument of this section is that 'diversity' as an internationally diffusable HR agenda within US MNCs was profoundly marked by the unresolved tensions in the diversity mix in the US, particularly between equal opportunities and 'business case' strands. These tensions have given rise to what might be called a 'contested institutional terrain'.

Writers frequently distinguish 'diversity', based on a voluntary corporate approach to 'valuing difference', from equal employment opportunities (EEO) or affirmative action (AA) agendas driven by a legislative programme requiring compliance from companies. In this paper, 'diversity' is used broadly to encompass both elements, while 'management of diversity' refers more specifically to the proactive and voluntary development of initiatives at company level.

The diversity agenda in the USA has been conditioned by a historical legacy of social and racial heterogeneity and associated tensions deriving first from slavery and then mass immigration (Kurowski, 2002). This has influenced diversity through two main routes. First, minorities, and women, drove a civil rights movement from the 1960s that, in parallel with mounting urban and racial tensions, changed the legislative and political environment for business (e.g. Bond and Pile, 1998). A series of legislative measures were passed (Dessler, 2001: chapter 2), beginning with the 1964 Civil Rights Act whose Title VII outlawed discrimination on the basis of race, colour, religion, sex, and national origin, and set up the Equal Employment Opportunities Commission (EEOC) to investigate and act on job discrimination. Executive orders were introduced requiring companies doing business with the US government to have written AA policies. Further legislation made it unlawful for employers to engage in pay discrimination on the basis of sex or age, or to discriminate against qualified disabled individuals. Thus employers were forced to take employment diversity into account, in a climate in which lapses could entail costly, high-profile legal action.

Second, demographic trends have shaped employers' diversity strategies. By 2000, ethnic minorities were 29 per cent of the total workforce, up from 22 per cent in the mid- 
1980s, with blacks accounting for 14 per cent and Hispanic groups 10 percent (EEOC, 2000). Women represented 47 per cent of the total labour force, and were in the majority among black groups. Moreover, minorities and women represented customers as well as potential employees: the combined buying power of African, Hispanic and Asian Americans is estimated to be in the region of $\$ 750 \mathrm{bn}$ (SHRM, 2002).

These demographic trends have been a major factor in the emergence of corporate diversity initiatives since the 1980s. The management of diversity has been underpinned, both for academic observers (e.g. Richard, 2000) and for practitioners (e.g. SHRM, 2002), by a move from a concern with compliance to consideration of the 'business case'. Essentially the business case rests on the competitive advantage to be derived from three broad elements: attracting and retaining skilled workers; servicing increasingly diverse markets; and improving organizational creativity and learning (e.g. Cox, 1994; Dass and Parker, 1999; SHRM, 2002). However, the evidence is far from conclusive on the link between diversity and business performance (Kochan et al., 2003; Jehn et al., 1999).

Despite the strength and visibility of the diversity agenda in the US, there are unresolved tensions both within and between the diversity and equal opportunities agendas. First, equality legislation in the US has lacked supporting systems of social regulation. Comparative analyses of equality (e.g. Whitehouse, 1992) have emphasized the importance to outcomes of interlocking legal and social regulations. That is, legal mechanisms, however strong, do not tend to deliver equality unless they are underpinned by embedded social mechanisms. For example, the inability of groups to enforce their legal rights as a result of factors such as gaps in their legal knowledge creates the space for continued discrimination at organizational level. In European countries, unions and collective bargaining are important elements of social regulation underpinning legal frameworks of equality, helping to build and enforce legal rights. However, such social supports are far weaker in the US business system.

Second, it has been suggested that diversity can offer a rationale for perpetuating inequalities, providing an 'alibi' for failing to address continuing unfairness experienced by groups of employees (Kirton and Greene, 2000: 114-115). Rival conceptions of the notion of AA have become a political and cultural battleground, and the 'management of diversity' rhetoric may be seen in the context of periodic bouts of corporate and political lobbying to roll back legislative regulation in favour of a voluntary corporate-level approach (cf. Dickens, 1999). The trend to corporate diversity agendas accelerated in the late 1980s at a time when the second Reagan administration was cutting back the monitoring and enforcement of 
EEO/AA policies (Bond and Pile, 1998). A symptom of the equivocal attitude of corporate America is the continuing proliferation of high profile litigation, backed by the EEOC, against some of the country's major employers (see e.g. EEOC, 2003). Multiplying legislative provisions to extend or clarify the legal framework, and a huge backlog of work for the EEOC (Baker, 2002), have created long delays for plaintiffs and the danger of what Bond and Pile (1998) call 'litigious gridlock': such developments, when coupled with periodic challenge to AA, raise questions the solidity of the 'regulatory pillar' of the institutional framework.

Third, there are tensions between a collective approach to managing diverse employee groups, and a more individualized approach focusing on individual needs and abilities which may serve to accentuate rather than decrease inequalities (e.g. Agócs and Burr, 1996; Liff, 1997). This may be illustrated by the definition of 'diversity' itself. It has become increasingly slippery, used in an all-embracing fashion to include not just the social categories of AA such as race and sex but a wide range of personal characteristics. For example, for the SHRM (2002), 'diversity encompasses an infinite range of individuals' unique characteristics and experiences, including communication styles, physical characteristics such as height and weight, and speed of learning and comprehension'. Underlying such uncertainties are unresolved debates between rival conceptions of equity based on paradigms of equality of treatment and equality of outcome, which themselves reflect the ongoing strains between multicultural and 'melting pot' conceptions of American society (Bond and Pile, 1998).

Fifth, and relatedly, it has been noted that the rhetoric of diversity tends to shift the emphasis from employee interests in equity and fairness to managerial interests in efficiency (Bond and Pile, 1998; Kirby and Harter, 2003). A 'business case' approach raises the possibility that the case may become weaker as market conditions change, or even that a business case may be articulated against diversity policies: for example, there may be management cost and control advantages in exploiting women workers, or in closing off recruitment systems to women or ethnic minorities (e.g. Dickens, 1999). Some observers have argued that the exploitation of ethnic and gender divisions has historically been a crucial management strategy in the US labour market (e.g. Gordon et al., 1982).

Finally, there is evidence (Bond and Pile, 1998) that the diversity agenda, both in its legislative and voluntarist forms, has provoked a significant backlash, particularly where it has coincided with periods of corporate downsizing and stagnating real incomes. Within 
companies, diversity programmes bring the danger of loss of status and security for white men, while organizational cultures have not changed enough to support diversity initiatives adequately: the outlawing of overt discrimination has encouraged the rise of underground or 'aversive' racism at work (Bond and Pile, 1998).

In short, therefore, the institutional embeddedness of diversity is in many respects uncertain, changeable and beset with tensions.

Against this somewhat ambiguous background, formal diversity management programmes are now well-developed in most large US companies. Three-quarters of the largest corporations had some form of diversity management in the late 1990s (Egan and Bendick, 2001: 2), incorporating a wide range of elements including leadership programmes; corporate values; recruitment and retention systems; career development, promotion and the management of high potentials; training programmes; structures of involvement such as 'diversity councils' and 'affinity groups'; community relations; and supplier relations.

The evidence on the management of diversity in US MNCs is limited, and studies have been small-scale (Egan and Bendick, 2001; Wentling and Palma-Rivas, 2000). However, it suggests that in the latter part of the 1990s, companies began to transfer diversity programmes to their overseas operations. Wentling and Palma-Rivas (2000) argue that this reflected US companies' increasingly diverse global workforce. Initiatives abroad were generally fewer and less aggressive. However, the basic framework of diversity tended to be the same as at home. This 'parallelism' (Egan and Bendick, 2001) was reflected in a common global mission and corporate values; the use of global diversity teams; common administrative structures; common training programmes; and affinity groups, particularly for women. However, foreign subsidiaries were generally given autonomy to adapt policy to local concerns.

US MNCs transferring diversity policies to the UK are not, of course, operating on a clean slate: there is an important regulatory context both in the European Union and in Britain (see Johnson and Johnstone, 2000). In most European countries there is a 'complaints-based' approach which seeks to redress discrimination against individuals. By contrast, the UK adopts an 'anti-discrimination law' approach aiming to counter inequality and protect vulnerable and disadvantaged groups. Thus legislation outlaws discrimination in pay and employment on the grounds of gender, national origin, ethnicity, and disability. The key pieces of legislation are the Sex Discrimination Act 1986, the Race Relations Act 1976, 
and the Disability Discrimination Act 1995. The European Union's Employment Directive of 2000 required the UK also to introduce new prohibitions on employment discrimination relating to religion, sexual orientation, and age. Regulations covering the first two came into force in December 2003, while age regulations will be enacted by 2006.

Nonetheless, while the UK legal tradition in this area draws on US legislation (Liff and Wajcman, 1996), it has generally emphasized equality of opportunity or 'equal treatment', rather than equality of outcomes, and positive discrimination has been generally discouraged. It is also argued (see Johnson and Johnstone, 2000) that the effectiveness of UK anti-discrimination legislation is undermined by the individual nature of the legal remedies. Unlike the US system of class actions, which acts as a 'cost-maximizing' deterrent to delinquent employers, in the UK each affected individual has to bring a separate claim. Further, the evolution of British equality legislation was quite different from the US; unions have played more prominent roles in its development through collective bargaining, lobbying, and direct legal action, both on behalf of members in specific test cases and against the UK government to secure general policy changes (see Colling and Dickens 2001; Heery 1998; McColgan 2002: 380-2).).

More broadly, the labour market context for diversity policy is markedly different in Britain. Although, as in the USA, race-based discrimination has emerged as a major policy issue at various junctures, ethnic minorities account for only 9 per cent of the total population in the UK, compared with nearly 30 per cent in the USA. In the UK, gender has been the primary basis of labour market segmentation (for example, 41 per cent of women work parttime in Britain, compared with 18 per cent in the US).

\section{Methodology}

The arguments of this paper are based on empirical data from a study of HRM in US MNCs in the UK, financed by the UK Economic and Social Research Council. This is part of a wider comparative study of US MNCs in Europe exploring the influence of the US business system on employment relations of US MNCs and their subsidiaries in different host environments.

Hall (2003: 393) refers to 'systematic process analysis' as a methodological approach in which the primary aim is to investigate the processes whereby hypothesized causal variables - in this case, institutional aspects of the US business system - generate (or fail to 
generate) a particular outcome, in this case a pattern of international transfer of diversity policies. This emphasis on processual issues favours the use of an in-depth case-study methodology rather than a quantitative large- $N$ approach. The former permits the detailed unravelling of complex causal linkages and in particular the dynamics of informal bargaining processes between HQ and subsidiary within MNCs, in a way not permitted by statistical analysis. Case studies are particularly appropriate where, as here, the precise nature and significance of the 'dependent variable' in its specific national-institutional context is itself problematic and in need of investigation. By the same token, however, we would acknowledge the limitation of a small- $N$ study which does not allow broad generalizations to be drawn about the patterns of occurrence of the dependent variable.

Detailed case studies (see table 1) were carried out between 1999 and 2003 in five US MNCs, in IT, chemically-based consumer and industrial products, engineering contracting, and mechanical engineering (two firms). We refer to these as the 'core' case studies. The companies were chosen in order to cover a range of industries with varying degrees of international integration of operations. They also encompass major differences in HR and employment relations traditions in the USA, particularly between traditionally unionized firms and sophisticated non-union companies. More limited access was obtained in a further eight companies. Data from seven of these firms have been excluded from the analysis as we were not able to obtain triangulating data from corporate HQ on the diversity issue. However, one further firm (Business Services), for which triangulation was obtained, is included in the analysis.

Pseudonyms are used since access was granted on condition of anonymity. For the same reason, description of particular incidents or policies is kept vague in some places to avoid identification.

[table 1 about here]

Data were collected from 118 respondents in the six companies. Interviews were conducted with senior HR, finance and operations managers in UK subsidiaries. In each of the five core companies, 5-10 non-managerial employees were interviewed, and in one, a group interview was conducted with six members of a site-based 'diversity council'. In all the 
companies, interviews were conducted with senior managers at US HQ. Interviews were also conducted in some cases at European and international business unit HQ. Respondents were asked about the existence of diversity policies; how these were devised, implemented and monitored; specific diversity issues that arose; the relationship between diversity and other policies such as working time and work-life balance; and the structures used to apply diversity policy.

Interviews were taped, transcribed, and coded using QSR N5 data analysis software. A wide range of documentary material was collected from source such as SEC filings and company websites. This was used to provide evidence of the formal language and profile of diversity initiatives in different companies. Information was collected from respondents on the nature of international diversity initiatives; the rationale of diversity policy; structures at local and HQ level for managing diversity; the mechanisms through which diversity policy was implemented, monitored and enforced; subsidiaries' reactions to transferred policies; and the tensions between transferred policy and local customary and legislative constraints.

'Diversity' was an 'emergent' issue, rather than a focus of the research from the outset. However, the longitudinal element of the case-study methodology permitted the exploration of diversity issues in all six companies once the issue had been identified as significant.

\section{Empirical findings: the transfer of workforce 'diversity' policies in US MNCs}

This section first considers the companies' domestic diversity agenda and the rationale for internationalizing it. It then describes the substance of international diversity policy. Finally, it explores the reaction of subsidiary management to the transfer of diversity initiatives, focusing on the power of subsidiaries to resist or modify central policy.

\section{The domestic diversity agenda and internationalization}

Most of the case-study companies had well-developed domestic policies for managing diversity, generally underpinned by a hard-headed business rationale. The three elements of a business case referred to earlier were present in varying degrees. The first was to maximize 'access to the pool of talented people' (HQ HR manager, Engco2), particularly those with scarce technical and professional skills. The second was to achieve a workforce composition 
more representative of the customer base. The third was to enhance creativity by avoiding a 'cloned' workforce and harnessing multiple perspectives - 'leveraging difference' as an HQ manager in Engco2 called it. In short, companies saw diversity as allowing them to compete effectively in labour markets as well as product markets, and to outwit competitors by exploiting the creativity of difference.

There were also tensions within domestic policy, however, reflecting wider strains in the diversity agenda discussed earlier. Thus at least three of the core case-study companies had been the subject of recent EEOC-initiated lawsuits for sexual and racial discrimination in their manufacturing plants. The EEO framework was seen as burdensome even where firms complied: in one firm, for example, HQ managers referred to the constraints imposed on managerial freedom of action by the stringent application in the courts of the principle of 'disparate impact' (i.e. where actions indirectly discriminate against a group), particularly in the context of downsizing and redundancy.

The uneasy coexistence of EEO and diversity agendas was present in the mindset of American HR managers. In the words of one (white, male) manager, 'when we say diversity, it's diversity in work locations, it is work assignments, if you look at myself, I've been in purchasing, I've been in HR, I've been in operations, I've been in logistics. That's workforce diversity, not the colour of my skin, my gender'. There was also evident concern with the 'backlash' against diversity. One (female) senior HQ manager spoke of the danger that white male employees' discontent with diversity would drive them into the arms of the union:

What will happen is the white males will look at it and will see that women, minorities, everybody else has somebody to speak for them in one fashion or another, or is protected in one fashion or another, who's going to look after me as the white male? I might go to a union and look at a union as being the only group that would look after or speak for me.

In this company, for which a non-union approach was a longstanding article of faith, it is easy therefore to see considerable strains emerging between diversity and employee relations strategies. Ironically, the development of diversity policy had been an indirect response to racial tensions in the US plants. The diagnosis was that 'HR was not seen to be independent in any way and was ... purely a tool of management', and the US response 'was to underline and enlarge essentially the independent role of HR as an advocate of employee interests'. The 
enhancement of the HR role provided the impetus for the emergence of systematic diversity policy (not just in the US but world-wide).

The business case logic favoured the extension of diversity policies to international operations, where competitive advantage required the ability to attract scarce labour market skills, and a refined understanding of national and regional characteristics. And with the globalization of markets, corporate learning and creativity at the international level was becoming increasingly important.

\section{Elements of international diversity programmes}

The global diversity structures tended to develop out of existing domestic structures. ITco, Engco2 and CPGco all set up global diversity 'leadership teams' which incorporated representatives from businesses and regions around the world in structures such as 'diversity councils'. This machinery was replicated at regional and country level and in some cases at individual sites. Engco2, for example, created site diversity councils at which managers and employees discussed the local application of corporate diversity policies. However, machinery was rarely as elaborate as domestically. (This and other aspects of international diversity policy in the core case-study companies are summarized in table 2 below.)

[table 2 about here]

Diversity was often incorporated as a corporate value within the companies' mission or values statements. Diversity programmes were extensively publicized on corporate websites, workforce diversity metrics were displayed, and a multitude of awards recognizing diversity achievements were trumpeted. Some companies also had global in-house awards for services to diversity. Finally, international diversity initiatives were sometimes accompanied by global training programmes. In Engco2, training was centrally mandated, designed and delivered in standardized form by consultants globally.

The substance of international diversity varied, but there were a number of common features. First, gender policies were pervasive, while policies on ethnicity, disability and sexual orientation were more variable from company to company. Policy on women included 'affinity groups' and mentoring systems for women employees, and targets for women in high potential groups, promotion pools, or managerial positions. Second, companies 
generally provided only a broad international framework rather than globally standardized policies. Within this framework, subsidiaries could develop locally appropriate policies. But subsidiaries could not evade or reject diversity: they were required (e.g. in CPGco, Engco2, and Business Services) to develop a diversity policy against which they would be judged. Third, the companies that most emphasized international diversity required subsidiaries to set targets against which they were closely monitored. In some cases, targets were promulgated centrally: e.g. Engco2 HQ set regions a target of one woman in place in regional leadership teams. Fourth, there was regular collection of diversity 'metrics' by higher levels and ultimately by head office. Finally, in CPGco and Engco2 notably, senior managers were set individual diversity targets within the performance management process. Metrics, such as improvements in employee satisfaction on diversity issues in periodic workforce surveys, were used in performance assessment alongside more qualitative measures.

\section{Perceptions of diversity in the subsidiaries}

The perception by US HQ managers was that diversity policies were successfully driving change globally. A CPGco HQ manager, for example, argued that targets for women in management positions were allowing women in the Japanese subsidiary to break out of their traditional ghetto of administrative and clerical roles.

But from the vantage point of the subsidiaries, while respondents were generally favourable to diversity as a concept, there was a strong perception that global policy was being driven by parochial US problems, leading to initiatives inappropriate for a non-US environment. In one company, European managers saw the globalization of the diversity agenda as a response to severe racial tensions in domestic US plants and to the ensuing litigation. They could not see why the resulting suite of policies for developing a more inclusive corporate culture should be transposed wholesale to European operations: 'the initial plan was rolling out a solution to the [US] situation, around the world, and many of us pushed back very hard against that' (UK HR manager).

Similarly, in Engco2, a UK HR manager complained that the corporate antiharassment policy referred to bodies like the Ku Klux Klan which were irrelevant in the British context. Monitoring of diversity was often biased towards American preoccupations. According to members of a UK plant-based diversity council in Engco2, US monitoring of ethnic groups in the workforce was based on American categories that were inappropriate in the UK; and with ethnic minority representation in Engco2's local labour market under 2 per cent, ethnic diversity was not a major priority. 
UK subsidiaries were also aware of tensions in the US parent over the implementation of diversity. As a UK HR manager reported, following a global HR directors' meeting at corporate HQ,

What I discovered was the most off-field mob in terms of responding to all this [diversity agenda] was, we've got a plant in Colorado... the HR guy there at the bar in the evening was very frank about how dismissive he was about all this stuff, you know he'd a plant full of cowboys and they weren't really interested in diversity, didn't mean much to 500 cowboys in Colorado, so everybody has their own response to this.

Targets, particularly for women in management positions, could be seen as excessively rigid by UK managers. European managers rejected the principle of affirmative action that was implicit in targets to increase the percentage of women managers, not only because it could be seen to be at odds with UK and EU legislation outlawing positive discrimination, but because of its demotivating impact on male managers. Several European managers in $C P G c o$ were sceptical about the principle of targets which they saw as doing little to remove the real barriers to the advancement of women and ethnic minorities in the company; such inhibitors included other aspects of US MNC practice, notably the pervasive long hours culture.

The thrust of subsidiary comment, therefore, was that global diversity policy was problematic in terms of local priorities. The advantages of diversity derived to a large degree from pressures and opportunities specific to the American business system, and even there they were not always apparent. To the extent that the potential for international competitive advantage existed, it could be negated by the diffusion of policy measures that were not suited to host environments. Finally, even though most managers were receptive in principle, few non-managerial respondents felt that diversity policy impacted significantly on them, with the occasional exception of diversity training.

\section{UK subsidiary responses: resistance, avoidance and accommodation}

The response of subsidiaries to the perceived 'parochialism' of global diversity policies can be explored in terms of Oliver's (1991) categories of strategic response to institutional pressures. Generally subsidiaries tried to negotiate the terms of application of policy in their local context. They were able to mobilize resources that allowed them to resist what they saw 
as inappropriate centrally-imposed policies. First, they exploited the legal constraints referred to above. This involved 'interpreting' the implications of the law. In CPGco, for example,

We have argued that if we were seen to have targets [for women in management positions] then that would implicitly be positive discrimination. I don't know strictly from a legal point of view whether that would be ... but I guess that's what essentially fended off too explicit a target. (UK HR manager)

Second, subsidiaries could also point to the 'objective' structural features of labour markets. In companies such as CPGco and Engco2, employees tended to be long-stayers, generations from the same family often worked side by side, and turnover rates were very low. (By contrast, turnover was around 12 per cent in key segments of the workforce in ITco, allowing diversity policy potentially to have a fairly rapid impact on workforce composition.) Such factors combined with stagnating or falling employee numbers, further inhibiting a change in workforce composition. Engco2 had taken steps to increase the proportion of women in the pool of temporary workers from which it recruited its permanent employees, but temps were the first to go in a downturn. Such structural factors were used to justify very limited progress on diversity goals. For example, in both major UK plants of Engco2, the proportion of women in shopfloor jobs was below 5 per cent; by comparison, in the sister plant in the US the figure was almost 40 per cent.

Finally, given the pervasive slipperiness of the concept, subsidiaries could deploy the rhetoric of diversity to build the case for alternative, Europe-centred, conceptions of diversity to challenge the corporate definition. Thus several companies questioned the lack of non-US managers in senior posts. Subsidiary managers stressed repeatedly that Europe was already 'diverse', and that in relevant respects the USA was not.

The outcome of this combination of structural constraints and rhetorical tactics was, de facto, a process of negotiation with the centre over the terms of application of diversity policy in the European subsidiaries. In $C P G c o$, HQ was frustrated at slow progress in achieving targets for women in senior posts; the subsidiary countered by stressing the law against quotas and positive discrimination but also proposed a locally more appropriate response based on encouraging women with management potential, pressing recruitment agencies to include more women on short lists, and establishing networks of women managers. This was seen as a strategy of support rather than one of 'positive discrimination'. In CPGco's manufacturing operation, similar accommodations were visible. Local managers 
accepted that some constructive response to HQ pressure was necessary, and indeed desirable, but tried to shape policy to local needs. As one manager put it, 'what we've learned how to do... is to listen to what they say and decide what we're going to do and put it under that same banner'.

There was an added incentive to negotiate over diversity where it impacted on a manager's individual targets and, potentially, his or her performance-related remuneration. In $C P G c o$, the operations manager realized that his HQ-based line manager would oblige him to include diversity objectives in his performance targets, but he had been successful 'in saying don't count, look at the behaviour, the things we've put in place, and measure me on how much progress I'm making with those'. Instead of setting quantitative targets, he launched an initiative with site unions to look at obstacles to diversity in the blue-collar workforce. In the same company, the UK HR manager's objectives were set by a US-based HR director whose responsibilities included global corporate diversity. However, the local manager resisted formal diversity objectives on the grounds that they ignored the great bulk of his day-to-day HR activity, under-emphasized local diversity initiatives, and created potential legal difficulties. The result was a wary, inconclusive dialogue:

I would say the process is we're circling one another about that whole issue.... In theory we're supposed to agree [objectives], and I guess we never really do. This is embarrassing, as an HR man.... But we are in the middle of a struggle with this over quite what global management of HR means.

\section{Discussion: the transfer of diversity policies, power, and institutions}

The findings show a pattern of uneasy subsidiary accommodation to transferred diversity policies. The 'isomorphic pulls' exerted by corporate headquarters were not sufficient to ensure what Oliver (1991) terms subsidiary 'acquiescence', that is full compliance in form and spirit with institutional pressures. The US diversity agenda rarely became assimilated to taken-for-granted normative and cognitive schemas of subsidiary managers, although conformity to the 'regulatory' pressures of HQ policy was generally observed. To put it another way, though diversity policy was 'implemented', the process of 'infusing with value' and 'internalizing' (Kostova, 1999) was at best incomplete. Although cases of open defiance 
were rare, direct resistance was occasionally evident, as in the stubborn resistance of the HR manager to agreeing diversity targets with his US boss.

Oliver's other categories of strategic response were also observed in the case companies. 'Compromise', in which the organization tries 'to balance, pacify, or bargain with external constituents' (Oliver, 1999: 154) was seen in CPGco which deflected HQ's targetsetting approach while offering concessions in the form of alternative support structures and initiatives to understand the causes of low ethnic and female participation. 'Avoidance', characterized by ritual conformity, could be detected in the lip service paid to diversity by subsidiaries even while their female and ethnic participation rate remained stubbornly low in absolute terms and relative to equivalent plants in the US.

The evidence also illustrates the contextual factors that generate this pattern of subsidiary responses. In particular, the institutional terrain of diversity was contested in a double sense. First, despite similarities, the regulatory, cognitive and normative domain of diversity and EEO was distinct in the US and the UK, making it harder for US HQs to assert the primacy of their own 'taken-for-granted' schemas. Thus subsidiary managers were able to mobilize their resistance on the basis of differences in regulatory frameworks of diversity in the two countries. Second, the domain of diversity was riven by tensions of principle, practice and interest within the US business system (and indeed within the UK). In other words, it was only partially institutionalized. This again made it difficult to establish the hegemony of a HQ conception of diversity policy, particularly since managers both at HQ and in the subsidiaries were aware of the stresses. In terms of Oliver's arguments (1999: 161), the perceived legitimacy of the diversity agenda was not strongly established in the minds of UK subsidiaries (or even in the US). To put the point differently, 'internalization' in the subsidiary seems unlikely if it has not even occurred at the centre. Part of the reason for the incomplete institutionalization of diversity appears to lie in unresolved debates about its efficiency. The perceived benefits of diversity were at best ambiguous, particularly in the UK context where the demographic forces for diversity were weaker than in the US. Such doubts over what Oliver calls 'economic fitness' (p.161) were again likely to inhibit full subsidiary compliance with the diversity agenda.

The findings throw light on the gambits of resistance and negotiation used by subsidiary managers to take advantage of their potential room for manoeuvre on diversity. They were able to derive bargaining resources from their rootedness within the specific institutional configuration of the host country, wielding arguments e.g. about legislative 
constraints. But at the same time, their capacity to deploy resources effectively depended, as Birkinshaw and Fry (1998) propose, on their ability to maintain credibility within the wider corporation. In part this was achieved by mobilizing appropriate 'vocabularies of motive' (Mills, 1963), i.e. rhetorical repertoires capable of legitimizing their proposed courses of action. An example of this is the way in which subsidiary managers justified resistance to diversity proposals on the grounds that these would hinder rather than advance the diversity agenda, and they were also careful to advance alternative proposals that would achieve the same objective.

These findings cast further doubt on 'competitive advantage' models of international transfer since they strongly suggest that the modification and 'hybridization' of diversity policy take place routinely. Subsidiary managers attempted to negotiate the terms of the transfer in ways which eroded the original content and intentions of the policy (although they sometimes tried to produce functional equivalents to central policy appropriate to local conditions). To put it another way, competitive-advantage-based models of transfer such as that of Taylor et al. (1996) under-emphasize issues around the 'context-generalizability' of policy - that is how far the policy may be transferred to other institutional contexts - and they systematically neglect the potential for 'resistive hybridization', based on the power resources of subsidiary actors, when policies is transferred to foreign operations. Conversely, while neo-institutionalists such as Kostova (1999) do not neglect the question of hybridization, they neglect the play of power and interests that attend it.

A further issue is how the range of diversity outcomes can be explained. More systematic generalization would require a large-scale survey approach. However, some tentative conclusions may be drawn from the case studies. Florkowski (1996) suggests that the nature of international diversity policy reflects a combination of product- and labourmarket pressures for diversity in the home and host business systems. This strategic contingency approach finds some support in our case-study data. Companies like ITco that were globally more integrated in their operations appeared more likely to have strong global diversity policies. Conversely, Eng Servs was highly multidomestic in operation because the engineering contracting sector needed to respond to highly local factors (see Colling and Clark, 2002). Companies whose markets both domestically and internationally were more diverse, especially in terms of gender and ethnicity, also had greater objective motivation for introducing diversity policies, as Florkowski's model predicts. 
However, the extent of international diversity policy in the case-study companies could not be entirely explained by such structural factors. Within-sector comparisons show significant differences. For example, in engineering, Engcol and Engco2 were medium-sized MNCs with overlapping product ranges. Yet Engcol had a minimalist international policy, while Engco 2 had a strong and relatively standardized global diversity programme. The case studies appear to demonstrate considerable space, within structural constraints, for managerial 'strategic choice'. Engco2 had a diversity programme that was directly in keeping with the philosophy of the founding family, still active within the company. In the early 1980s the founder had issued a frequently referred-to statement on diversity which spoke of the need to abandon cherished prejudices concerning sex, race, accent or academic qualifications. This in turn was in line with Engco2's distinctive employee relations strategy, based on independent, company-based unions, a strong internal labour market, and high workforce commitment. In short, structural constraints leave a considerable margin of manoeuvre within which managers can exert choices.

A final question is why US MNCs have sought to internationalize the diversity agenda given its at best ambiguous contribution to international competitive advantage. A first possibility is that diversity is part of a wider management approach that is seen to have competitive advantage as a whole. Companies might, for example, construct 'ideological' sources of international competitive advantage by leveraging an explicit corporate philosophy, as in Engco2 and, to a lesser degree, in CPGco. 'Diversity' could then be seen as one element in a company-specific, internationally-focused corporate culture. In short, the transfer of a well-tried recipe might have competitive advantage as a mode of global operation, even if individual elements might not be advantageous. ${ }^{2}$ However, this does not deal with the serious questions raised by UK respondents in these and other companies about the value of the diversity agenda.

An alternative explanation raises more profound questions over the competitive advantage approach. This is that companies may adopt international diversity policies even when this does not lead to competitive advantage. There are a number of elements to this. One line of argument derives from the systemic dominance effects arguments of Smith and Meiksins (1996). The dominance of the US business model in the world economy encourages a presumption by US MNCs that domestically-devised policies such as diversity management are superior. Such policies may have greater legitimacy, both domestically and abroad, because they are associated with a dominant business system. Moreover, dominance itself 
gives rise to considerable power resources to facilitate transfer. For example, there may be a high density of MNCs from a dominant parent in a given host country, creating more favourable conditions for the transfer and implantation of home practices in the host. These considerations open the possibility for policies to be transferred despite the fact that they do not confer competitive advantage as e.g. Taylor et al. (1996) presume.

A further element relates to what might be called the 'technology' of knowledge transfer in US firms. One important aspect of US business dominance was the early emergence of 'organizational capabilities' (Chandler, 1990; see also Baron et al., 1986) in the form of standardized control systems that allowed consistent management of operating units spread across dispersed geographical territories and product markets. Such systems subsequently provided the basis for the internationalization of American companies (Chandler, 1990). Once global management structures have been introduced they provide a mechanism for transmitting further policies globally. In CPGco, 'you set up a global HR organization and it's got to do something to justify its global title. So, you know, we've got this big [diversity] programme, why shouldn't it be rolled out in China or Brazil or whatever...?' (UK manager). In other words, policies are disseminated internationally because the organizational technology exists. With the routine presence in US MNCs of what might be terms 'low inertia' transmission mechanisms, based on formalized, standardized transmission channels, the marginal costs of international policy propagation are likely to be low. Thus policies may be internationalized even when competitive advantage is absent.

\section{Conclusions}

Diversity is a useful issue through which to examine the question of how policy is transferred internationally within MNCs since the embeddedness of the diversity agenda within the domestic US environment can be traced in a relatively straightforward manner. It has been argued that international diversity initiatives in US MNCs have primarily been outgrowths of domestically driven policies. Their transfer abroad has made assumptions about contextgeneralizability that are sometimes inappropriate. As a result, subsidiary managers use available power resources to shape the content and impact of policy. The implications are farreaching. Top-down, senior-management-driven rationalistic models of transfer are inadequate since they neglect the impact of conflicts of perception about 'appropriateness' among actors at different organizational levels, and the resources they can deploy to pursue 
their interests. Equally, however, current institutional analysis has shortcomings since it fails to see institutionalization as a contested process cross-nationally. We have argued that by combining the insights of institutionalism with a power and interests perspective, and by locating power resources in the context of comparative-institutional analysis, a more nuanced understanding of the transfer process is possible.

Further research could explore these issues by looking at a wider range of policy transfers. Is 'diversity' a special case, or would the transfer of other HR policies exhibit similar features? It seems likely that other issues will provoke yet greater 'resistive hybridization' than in the case of diversity. This is particularly true where transferred policies directly confront core interests of important interest groups in the subsidiary, including employees and unions as well as managers. For example, Ortiz (1998) found that unions in the UK subsidiary of a US MNC resisted the introduction of teamworking because it challenged their core organizational interest in the control of work organization. In general, national institutional frameworks appear to provide a multiplicity of potential resources with which local subsidiary actors can challenge the transfer of policies or shape their implementation in ways unforeseen by headquarters. Conversely, other policies may be more easily internalized and induce more compliant responses from the subsidiary. This may be the case with innovative payment systems, where the cognitive and regulatory frameworks may be more isomorphic between the UK and the US.

A second area for further research is the influence of the host environment. The findings have been drawn from one host, which is institutionally close to the US in many respects. Given the importance of institutional constraints within a national business system as a power resource for local subsidiary actors, extending the research to further host countries is likely to provide greater insight into the dynamics of transfer in MNCs. In particular, exploration of more highly 'regulated' business systems such as Germany, where the basis of economic coordination relies more on supra-market principles than in the British or American 'liberal market' model (Hall and Soskice, 2003), would throw more light on the robustness of transferred practices in the face of pressures for resistive hybridization. 


\section{Endnotes}

1 'Isomorphism' refers to the extent to which organizations adopt the same practices as other organizations within their environment (Zucker, 1977).

${ }^{2}$ We are indebted to an anonymous JIBS reviewer for this insight. 


\section{Acknowledgements}

The research on which this paper is based is funded by the UK Economic and Social Research

Council, Award no. R000238350. We are very grateful to our colleague on the US multinationals project, Tony Edwards, for his valuable comments on earlier drafts of the paper, and to other members of the research team, Peter Butler, Ian Clark and Len Holden, for their contribution. We would also like to thank our colleagues in the German, Irish and Spanish country teams, led by Hartmut Waechter (University of Trier), Paddy Gunnigle (University of Limerick), and Javier Quintanilla (IESE Business School) respectively, for access to interview data from the different country studies. Finally we are most grateful to two anonymous JIBS reviewers for their focused and constructive comments, and to JIBS' Departmental Editor, Professor Mari Sako. 


\section{References}

Agócs, C. and Burr, C. 1996. Employment equity, affirmative action and managing diversity: assessing the differences. International Journal of Manpower, 17(4/5): 30-45.

Baker, Aaron. 2002. Access vs Process in Employment Discrimination: Why ADR suits the US but not the UK. Industrial Law Journal, 31(2): 113-34.

Baron, James, Dobbin, Frank, and Jennings, P.Devereux. 1986. War and peace: the evolution of modern personnel administration in U.S. industry, American Journal of Sociology, 350-85.

Bartlett, C. and Ghoshal, S. 1998. Managing Across Borders (2nd ed.), London: Hutchinson.

Birkinshaw, Julian \& N. Fry. 1998. Subsidiary initiatives to develop new markets. Sloan Management Review, 39(3): 51-62.

Birkinshaw, Julian \& N. Hood. 1998. Multinational subsidiary evolution. Academy of Management Review.

Birkinshaw, Julian. 2000. Entrepreneurship in the Global Firm: Enterprise and Renewal. London: Sage.

Bond, Meg A. \& Jean L. Pile. 1998. Diversity Dilemmas at Work. Journal of Management Inquiry, 7(3): 252-69.

Boyer, R., Charron, E., Jürgens, U., Tolliday, S. 1998. Between Imitation and Innovation. The transfer and hybridization of productive models in the international automobile industry, Oxford: OUP.

Chandler, Alfred. 1990. Scale and Scope. The dynamics of industrial capitalism, Cambridge, Mass: Belknap Press.

Colling, T. and I. Clark. 2002. Looking for "Americanness": home-country, sector and firm effects on employment systems in an engineering services company, European Journal of Industrial Relations 8(3): 301-324.

Colling, T. and Dickens, L. 2001. Gender equality: a new basis mobilisation? In Noon, M. and Ogbonna, E. (eds) Equality, Diversity and Disadvantage in Employment, Basingstoke: Palgrave, 136-156.

Cox, T. 1994. Cultural Diversity in Organizations, San Francisco: Berrett-Koehler.

Cutcher-Gershenfeld, J. et al. 1998. Knowledge-Driven Work: unexpected lessons from Japanese and United States Work Practices, Oxford: OUP. 
Dass, P. and Parker, B. 1999. Strategies for managing human resource diversity: from resistance to learning, Academy of Management Executive, 13(2): 68-80.

Dessler G. 2001. A Framework for Human Resource Management, 2nd ed. Upper Saddle River N.J.: Prentice Hall.

Dickens, L. 1999. Beyond the business case: a three-pronged approach to equality action, Human Resource Management Journal, 9(1): 9-19.

DiMaggio, P.J. \& W. W. Powell. 1983. The iron cage revisited: Institutional isomorphism and collective rationality in organizational fields. American Sociological Review, 48: 147-60.

Doeringer, P., Lorenz, E. and Terkla, D. 2003. The adoption and diffusion of high-performance management: lessons from Japanese multinationals in the West, Cambridge Journal of Economics, 27: 265-286.

Edwards, Tony \& Anthony Ferner. 2004. Multinationals, reverse diffusion and national business systems. Management International Review, Special issue(1/2004): 49-79.

EEOC. 2003. Caterpillar goes to court rather than conciliate shocker, http://www.eeoc.gov/press/8-13b03.html.

EEOC. 2000. Occupational Employment in Private Industry by Race/Ethnic Group/Sex, and by Industry, United States, 2000, [www document] http://www.eeoc.gov/stats/jobpart/2000/national.html (accessed 24 July 2003).

Egan, M. and Bendick, M. 2001. Workforce Diversity Initiatives of US Multinational Corporations in Europe. Unpublished paper, Washington.

Evans, P. and Lorange, P. 1989. The Two Logics Behind Human Resource Management, In P. Evans, Y. Doz, and A. Laurent (eds.) Human Resource Management in International Firms. Change, Globalization, Innovation, Basingstoke: Macmillan, pp. 144-161.

Ferner, A. 1997. Country of Origin Effects and Human Resource Management in Multinational Companies, Human Resource Management Journal, 7(1): 19-37.

Ferner, A. and M. Z. Varul. 2000. "Vanguard" subsidiaries and the diffusion of new practices: a case study of German multinationals, British Journal of Industrial Relations, 38(1): 115-140.

Florkowski, G. 1996. Managing diversity within multinational firms for competitive advantage, in E. Kossek and S. Lobel (eds.) Managing Diversity, Oxford: Blackwell, pp. 337-364. 
Gordon, David M., Richard Edwards \& Michael Reich. 1982. Segmented Work, Divided Workers : The Historical Transformation of Labor in the United States. Cambridge: Cambridge University Press.

Gupta, A. and Govindarajan, V. 1991. Knowledge Flows and the Structure of Control within Multinational Corporations, Academy of Management Review, 16(4): 768-792

Hall, P. 2003. ‘Aligning ontology and methodology in comparative politics', in J. Mahoney and D. Rueschemeyer (eds.) Comparative Historical Analysis in the Social Sciences, Cambridge: CUP, pp. 373-404.

Hall, Peter \& David Soskice, editors. 2001. Varieties of Capitalism. Oxford: OUP.

Heery, E. 1998. Campaigning for Part-Time Workers, Work Employment and Society, 12: 351-66.

Hofstede, G. 1980. Culture's Consequences, London: Sage.

Jehn, K. Northcraft, G., Neale, M. 1999. 'Why differences make a difference: a field study of diversity, conflict, and performance in workgroups', Administrative Science Quarterly, 44(4): 741-763.

Johnson, Linda \& Sue Johnstone. 2000. The Legislative Framework.In Kirton, Gill \& Anne-Marie Greene, editors, The Dynamics of Managing Diversity. London: Butterworth/Heinemann.

Kirby, Erika L. \& Lynn M. Harter. 2003. Speaking the language of the bottom-line: the metaphor of “managing diversity". The Journal of Business Communication, 40(1): 28-49.

Kirton, Gill \& Anne-Marie Greene. 2000. The Dynamics of Managing Diversity: A Critical Approach. Oxford: Butterworth-Heinemann.

Kochan, Thomas et al. 2003. The effects of diversity on business performance: Report of the diversity research network, Human Resource Management, 42(1): 3-21.

Kostova, Tatiana \& Srilata Zaheer. 1999. Organizational legitimacy under conditions of complexity: the case of the multinational enterprise. Academy of Management Review, 24(1): 64-83

Kostova, Tatiana \& Kendall Roth. 2002. Adoption of an organizational practice by subsidiaries of multinational corporations: institutional and relational effects. Academy of Management Journal, 35(1): 215-33.

Kostova, Tatiana. 1999. Transnational transfer of strategic organizational practices: A contextual perspective. Academy of Management Review, 24(2): 308-24.

Kurowski, L. 2002. Cloaked culture and veiled diversity: why theorists ignored early US workforce diversity, Management Decision, 40(2): 183-91. 
Lam, Alice. 1997. Embedded firms, embedded knowledge. Organization Studies, 18(6): 973-96.

Lam, Alice. 2003. Organizational Learning in Multinationals: R\&D Networks of Japanese and US MNEs in the UK. Journal of Management Studies, 40(3): 673-703.

Lane, Christel. 1989. Management and Labour in Europe. The Industrial Enterprise in Germany, Britain and France. Aldershot: Edward Elgar.

Liff, Sonia and Wajcman, Judy. 1996. "Sameness" and "difference" revisited: which way forward for equal opportunity initiatives?, Journal of Management Studies, 33(1): 79-94.

Liff, Sonia. 1997. Two routes to managing diversity: individual differences or social group characteristics. Employee Relations, 19(1): 11-26.

Martínez, Z. and Ricks, D. (1991) 'Multinational parent companies' influence over human resource decisions of affiliates: U.S. firms in Mexico', Journal of International Business Studies, 20(3): $465-488$.

McColgan, A. 2002. Discrimination Law: Text, Cases and Materials. Oxford: Hart.

Mills, C. Wright. 1963. The New Men of Power. America's Labor Leaders. New York: Harcourt Brace.

Morgan, G., Kristensen, P. H. and Richard, W. (2001) The Multinational Firm: organizing across institutional and national divides, Oxford: OUP.

Oliver, Christine. 1991. Strategic responses to institutional processes. Academy of Management Review, 16(1): $145-79$.

Pfeffer, J. and Salancik, G. 1978. The External Control of Organizations: A resource dependence perspective, New York: Harper \& Row.

Richard, O. 2000. 'Racial diversity, business strategy, and firm performance: a resource-based view', Academy of Management Journal, 43(2): 164-177.

Rosenzweig, P. and Nohria, N. 1994. Influences on human resource management practices in multinational corporations, Journal of International Business Studies, 25(2): 229-251.

Rosenzweig, P. and Singh, J. 1991 Organizational environments and the multinational enterprise, Academy of Management Review, 16(2): 340-61

Schuler, R. Dowling, P. and deCieri, H. 1993. An integrative framework of strategic international human resource management, International Journal of Human Resource Management, 1(4): 717-674.

Scott, W. Richard. 1995. Institutions and organizations. Thousand Oaks, CA: Sage. 
SHRM 2002 Diversity Initiative, [www document] http://www.shrm.org/diversity (accessed 24 July 2003).

Smith, Chris \& P. Meiskins. 1995. System, Society and Dominance Effects in Cross-National Organisational Analysis. 'Work, Employment and Society, 9(2): 241-67.

Szulanski, Gabriel. 1996. Exploring Internal Stickiness: Impediments to the Transfer of Best Practice within the Firm. Strategic Management Journal, 17(Winter Special Issue): 27-43.

Taylor, S., Beechler, S., Napier, N. 1996 Toward an Integrative Model of Strategic International Human Resource Management, Academy of Management Review, 21(4): 959-985.

Tempel, Anne \& Peter Walgenbach. 2003. Global Standardization of Organizational Forms and Management Practices? Combining New Institutionalism and the Business-Systems Approach. Erfurt.

Tolliday, S., Boyer, R., Charron, E. and Jürgens, U. 1998 Introduction: between imitation and innovation: the transfer and hybridization of productive models in the international automobile industry', in R. Boyer et al. (eds.), 1-19.

Wentling, R. and Palma-Rivas, N. 2000. Current status of diversity initiatives in selected multinational corporations, Human Resource Development quarterly, 11(1): 35-60

Wever, K. S. 1995 Negotiating competitiveness: employment relations and organizational innovation in Germany and the United States, Boston: Harvard Business School.

Whitehouse, G. 1992. Legislation and labour market gender inequality: an analysis of OECD countries. Work Employment and Society, 6(1): 65-86.

Whitley, Richard. 1999. Divergent Capitalisms: The social structuring and change of business systems. Oxford: Oxford University Press.

Whitley, Richard. 2001. How and why are international firms different? In Morgan, Glenn, Peer Hull Kristensen, \& Richard Whitley, editors, The Multinational Firm: organizing across institutional and national divides, Oxford: Oxford University Press, 27-68.

Zanfei, A. 2000. Transnational firms and the changing organisation of innovative activities. Cambridge Journal of Economics, 24: 515-42.

Zucker, Lynne G., editor. 1988. Institutional Patterns and Organizations: Culture and Environment. Cambridge, MA: Ballinger. 
Table 1 - Case study firms

Core case studies

\begin{tabular}{llcc}
\hline firm & sector & \multicolumn{2}{c}{ number of respondents } \\
& & UK subsidiary & $H Q^{*}$ \\
\hline Engco1 & mechanical engineering & 19 & 4 \\
Engco2 & mechanical engineering & 18 & 11 \\
Eng Servs & civil engineering contracting & 18 & 5 \\
CPGco & chemical-based consumer and & 15 & 8 \\
ITco & professional goods & 14 & 3 \\
Business Services & management consulting & 2 & 32
\end{tabular}

* 'HQ' refers to interviewees based US corporate headquarters, at international business unit headquarters (e.g. product divisions), or regional headquarters (e.g. European region); of the 36 respondents in this column, 22 were in US-based corporate or business unit HQs.

$\dagger$ Case studies where only limited access was secured but which nevertheless produced data of some value 
Table 2 - Summary of diversity policy in selected case-study companies

\begin{tabular}{|c|c|c|c|c|c|}
\hline & CPGco & Engcol & Engco2 & Eng Servs & ITco \\
\hline $\begin{array}{l}\text { diversity as a global } \\
\text { corporate value }\end{array}$ & $\begin{array}{l}\text { yes - diversity linked } \\
\text { to respect for } \\
\text { individual } \\
\text { aim to become a } \\
\text { global leader in } \\
\text { integrating diversity } \\
\text { into the business }\end{array}$ & $\begin{array}{l}\text { yes - 'diversity' } \\
\text { includes 'skills, } \\
\text { abilities, experiences } \\
\text { and cultural } \\
\text { backgrounds' }\end{array}$ & $\begin{array}{l}\text { yes - corporate } \\
\text { values include } \\
\text { embracing diversity, } \\
\text { defined as } \\
\text { employees' 'diverse } \\
\text { perspectives' }\end{array}$ & no & $\begin{array}{l}\text { yes - diversity and } \\
\text { inclusion as integral } \\
\text { to corporate culture }\end{array}$ \\
\hline $\begin{array}{l}\text { global structures of } \\
\text { diversity }\end{array}$ & $\begin{array}{l}\text { strong } \\
\text { internationalization } \\
\text { of domestic diversity } \\
\text { concerns } \\
\text { chief diversity officer } \\
\text { responsible for global } \\
\text { policy } \\
\text { global employee } \\
\text { diversity networks } \\
\text { questions on 'valuing } \\
\text { diversity' in periodic }\end{array}$ & no & $\begin{array}{l}\text { strong } \\
\text { internationalization } \\
\text { of diversity policies } \\
\text { international } \\
\text { diversity } \\
\text { implemented through } \\
\text { corporate diversity } \\
\text { council } \\
\text { diversity champions } \\
\text { in each business unit } \\
\text { site-level 'diversity }\end{array}$ & $\begin{array}{l}\text { no - virtually no } \\
\text { internationalization } \\
\text { of domestic diversity } \\
\text { policy }\end{array}$ & $\begin{array}{l}\text { strong } \\
\text { internationalization } \\
\text { of diversity policy } \\
\text { led by senior vice- } \\
\text { president } \\
\text { emphasis on } \\
\text { customer diversity } \\
\text { driving workforce } \\
\text { diversity initiatives } \\
\text { multiplicity of } \\
\text { diversity networks }\end{array}$ \\
\hline
\end{tabular}




\author{
global staff opinion \\ survey \\ global diversity \\ awards
}

councils' responsible

for local diversity

initiatives

international

diversity awards for

pioneering sites

global anti-

harassment policy

global target-setting

yes

and monitoring compulsory emphasis

on women in global

diversity policies;

flexibility for local

subsidiaries to

designate other

diversity groups

global targets for

women in senior

positions no

although general

concerns with

increasing

representation of

non-Americans in

leadership teams

universal gender

component to plans,

but other components

left to locality

global monitoring of and affinity groups

geog1

encol

'custc

initia

locali

introc

'care

UK

yes

no formal targets/-

quotas in Europe but

unpublicized target

'ranges' e.g. for

women

discreet tracking of

key diversity groups

at local/regional level

- e.g. metrics on new

hires, women in yes

ethnic

balan

criter

moni

intake

outco

globa

ethnic

balan

prom 
senior managers are

set diversity targets

as part of corporate

framework of

accountability;

proportion of

remuneration linked

to diversity metrics diversity metrics

(women and ethnic

minorities)

quarterly monitoring

of subsidiary

diversity action plans

targets for diverse

groups in leadership

positions

senior managers'

performance

appraisal linked to

diversity objectives

and metrics

compulsory

no

monitored by HQ management/

executive positions

etc.

$\begin{array}{ll}\text { international } & \text { diversity/harassment no } \\ \text { diversity training } & \text { training compulsory } \\ & \text { but mainly devolved } \\ & \text { to subsidiaries }\end{array}$

standardized

diversity training

world-wide,

no

HQ 